\title{
Pubertal development, physical activity, and sedentary behavior among South Korean adolescents
}

\author{
Eun-Young Lee, Valerie Carson, and John C. Spence* \\ Faculty of Physical Education and Recreation, University of Alberta, Edmonton, Canada
}

Copyright: (C) 2017 E.-Y. Lee et al. This is an open access article licensed under the Creative Commons Attribution License (http://creativecommons.org/licenses/by/4.0/).

\begin{abstract}
Background: Sex differences in physical activity (PA) and sedentary behavior (SB) are well-established. However, recent research suggested that variations in pubertal development may explain sex differences in PA and SB among adolescents. Objective: This study examined whether pubertal development mediates the relationship between sex and PA, and SB respectively. Methods: The 2012 Korea Youth Risk Behavior Web-based Survey included data from 74,186 students in grades 7 to 12 (mean age $=14.94 \pm 1.8 ; 48.5 \%$ girls). Pubertal development was indicated by the year in which the student reported they had experienced menarche for girls and semenarche for boys. Testing for mediation involved a bootstrapping resampling approach with self-reported PA and SB as criterion variables and taking into account covariates (chronological age, body mass index, school type, household income, and parental education). Results: Boys engaged in PA more frequently (3.30 \pm 2.1 vs. $2.29 \pm 1.7$ day/week) and spent less time in SB $(2.75 \pm 1.2$ vs. $2.93 \pm 1.2 \mathrm{hr} /$ day $)$ than girls. Direct effects were found between sex and PA $(\beta=-0.58 \pm .01$; $p<.05)$, and sex and SB $(\beta=0.17 \pm 0.01 ; p<.05)$. Pubertal development did not significantly mediate the relationship between sex and PA ( $\beta=0.00$; bias-corrected 95\% confidence interval [BC 95\% CI] [-0.01, 0.01]). Though pubertal development significantly mediated the association between sex and SB, the effect was small $(\beta=0.01$; BC 95\% CI [0.00, 0.02]). Conclusions: Sex appears to be an important predictor of PA and SB. Nonetheless, it is most likely that a combination of individual (e.g., psychological, biological) and sociocultural factors contribute to adolescents' movement behavior.
\end{abstract}

Keywords: puberty, adolescence, energy expenditure, KYRBS

\section{Introduction}

Sex is a well-recognized individual-level correlate of physical activity (PA) and sedentary behavior (SB) in the adolescent population. In general, boys are more physically active than girls (Colley et al., 2011) and, though variations exist by type (Leatherdale \& Harvey, 2015), girls spend more time in SB (Colley et al., 2013). Given the health benefits of PA and the negative health implications of SB (Carson et al., 2016; Poitras et al., 2016), health promotion strategies have focused on tailoring interventions by sex. However, emerging evidence suggests that the roots of the sex differences may be more complex, and that understanding sexual dimorphism in pubertal development may help to

\footnotetext{
* Address for correspondence: John C. Spence, Sedentary Living Lab, Faculty of Physical Education and Recreation, University of Alberta, 3-113 Van Vliet Complex, Edmonton, AB Canada T6G 2H9. E-mail: jc.spence@ualberta.ca
}

better explain individual variations in PA and SB than sex (Eisenmann \& Wickel, 2009; Sherar, Cumming, Eisenmann, Baxter-Jones, \& Malina, 2010).

Pubertal development refers to progress towards the mature state in humans, and can be measured in skeletal, dental, reproductive, and/or neuroendocrine systems (Cumming et al., 2012). Pubertal development is known to influence several aspects of human physiology and behavior (Dorn, Dahl, Woodward, \& Biro, 2006). In the Western context, pubertal development appears to explain the sex differences in PA and $\mathrm{SB}$ of growing children and adolescents (Cumming, Standage, Gillison, \& Malina, 2008; Rodrigues et al., 2010; Sherar, Esliger, Baxter-Jones, \& Tremblay, 2007; Thompson, Baxter-Jones, Mirwald, \& Bailey, 2003). Specifically, differences in PA disappeared when maturity-related variation between sexes (i.e., girls experience puberty approximately two years earlier than boys) was controlled in a Canadian adolescent sample (Thompson et al., 2003). Similarly, 
sex differences in SB were attenuated when pubertal development was controlled among Portuguese adolescents aged 13 to 16 years (Rodrigues et al., 2010). These findings suggest that pubertal development may mediate the associations of sex with PA and SB. Sex differences in PA and SB are also evident among adolescents in South Korea (Korea thereafter). Specifically, boys engage in more organized sport, PA, and physical education (PE), and less SB than girls (Song et al., 2016). As for the role of pubertal development, negative direct and mediated effects were observed for body fatness, perceived barriers of PA and self-efficacy on PA in a sample of Korean girls (Lee, An, et al., 2016). Furthermore, an indirect effect of pubertal development, via body mass index (BMI), on screen time existed among a national sample of Korean boys (Lee \& Spence, 2016). Given these findings, pubertal development may also play a role in the apparent sex differences in PA and SB among Korean adolescents.

Examining the potential role of pubertal development on PA and SB can offer insights into the foundations of behavior during these formative years. Specifically, it may help researchers, policy makers, and practitioners to know optimal times to intervene (i.e., pre- or post-puberty) for PA promotion among adolescents. Furthermore, age-related decline in PA and increase in SB may also be explained by taking individual differences in pubertal development into account (Cumming et al., 2008; Eisenmann \& Wickel, 2009; Goran, Gower, Nagy, \& Johnson, 1998; Sherar et al., 2007; Thompson et al., 2003). For instance, an energy-conserving mechanism occurs in the pubertal female body to develop reproductive capacity, resulting in decreased total energy expenditure (Goran et al., 1998). This mechanism, in turn, also explains greater increase in energy expenditure and physical capacities (i.e., peak oxygen uptake) at the onset of puberty in males than females (Bitar, Vernet, Coudert, \& Vermorel, 2000). Therefore, recognizing pubertal development may help researchers to better understand potential factors influencing both age and sex differences in PA and SB among adolescents. Because the perception of pubertal development and its influence on behavior may vary by demographic characteristics (Patton \& Viner, 2007; World Health Organization [WHO], 2011), identifying whether pubertal development attenuates associations of sex with PA and SB in different cultural groups is of interest.

The purpose of this study was to examine whether pubertal development mediated the relationships of sex with PA and SB in a representative sample of Korean adolescents. Based on the results of the previous literature (Cumming et al., 2008; Rodrigues et al., 2010; Sherar et al., 2007; Thompson et al., 2003), it was hypothesized that pubertal development would mediate these associations.

\section{Materials and methods}

\section{Participants and procedures}

The $8^{\text {th }}$ Korea Youth Risk Behavior Web-based Survey (KYRBS) was the source of data for this study. The KYRBS is an annual, cross-sectional, nationwide school-based web survey that monitors health risk behaviors among Korean adolescents in Grades 7 to 12 , which is administered by the Korea Centers for Disease Control and Prevention (KCDC) in collaboration with the Ministry of Education, Science, and Technology and the Ministry of Health and Welfare (2012). It includes a 129-item questionnaire developed by a committee with expertise in the related fields. Core information includes background (e.g., age, sex), health behaviors (e.g., smoking, alcohol use, physical activity) and health outcomes (e.g., self-reported health, obesity) (KCDC et al., 2012).

Participating schools were selected based on geographical regions $(n=16)$ and types of schools (i.e., middle schools, regular and specialized high schools). Teachers were assigned by principals in each school to administer the survey. On a registered date, students were led to a computer laboratory by the teacher and were asked to read an information letter before beginning the online survey. Participation in the survey was anonymous and voluntary. Each survey was administered during regular school hours for 40-50 minutes (KCDC et al., 2012). The KYRBS received approval on the study protocol from the KCDC (approval number: 11758; KCDC et al., 2012). Detailed information regarding the survey methodology, including validity and reliability of the KYRBS is published elsewhere (KCDC, 2009; Kim et al., 2016). Among 76,980 students from 400 middle and 400 high schools who participated (response rate: $96.4 \%$ ), those with missing values for height and weight ( $n=2,794)$ were excluded, leaving a total of 74,186 students ( $48.5 \%$ girls) included in the analyses. The age and sex distributions of participants were not significantly different between the sample included in the analyses and those excluded $(p>.05)$.

\section{Measures \\ Pubertal development}

The year of menarche (i.e., first menstruation) for girls and the year of spermarche (i.e., first ejaculation; also refer to as semenarche or oiarche) for boys were used as indicators of pubertal development. Menarche is a distinctive and commonly used measure of pubertal 
timing among girls, while spermarche has also been used to estimate pubertal development for boys in previous studies (Patton \& Viner, 2007; WHO, 2011). The KYBRS included one multiple-choice item related to pubertal development. The question was "When did you experience your first menstruation/ejaculation?". Response options were scaled from 1 (have not yet experienced) to 14 (Grade 12). For data analyses, pubertal development was recoded so that lower scores indicated early development and higher scores indicated late development based on the average Grade or year of experiencing pubertal development (Grade 6 or 12 years for girls and Grade 7 or 13 years for boys). For example, students who had indicated they experienced menarche/spermarche at Grade 12 were recoded to 13, and those who had not yet experienced menarche/spermarche were recoded to 14 .

\section{Physical activity}

Leisure-time PA was assessed using a question translated from the Youth Risk Behavior Surveillance System (YRBSS) questionnaire (YRBSS, 2016). Validity against accelerometry and test-retest reliability of the scale were reported previously (Troped et al., 2007). In addition, acceptable reliability (kappa $=0.41-0.54)$ of the PA measure among Korean adolescents was reported previously (KCDC, 2009). The question asked participants to answer the number of days that they engaged in PA resulting in heart rate increase or shortness of breath for more than 60 minutes. Response options were no participation at all (1) to seven days a week (8).

\section{Sedentary behavior}

SB was assessed using questions translated from the YRBSS questionnaire (YRBSS, 2016). Acceptable reliability $(\mathrm{kappa}=0.55)$ of the $\mathrm{SB}$ measure among Korean adolescents was reported previously (KCDC, 2009). The questions asked, "Other than educational purposes, 1) how many hours a day did you spend in your leisure time watching television, playing video games, internet surfing, or chatting with friends during the last five weekdays and 2) how many hours a day did you spend in your leisure time watching television, playing video games, internet surfing, or chatting with friends on the last two weekends?". Items were scaled from 1 ( $<1 \mathrm{hr} /$ day) to 5 ( $\geq 4 \mathrm{hrs} /$ day). Responses for the two items were weighted and averaged ([weekday $\times 5+$ weekend day $\times 2] / 7)$.

\section{Covariates}

Chronological age, school type (i.e., middle school, regular high school, and specialized high school), economic status, parental education levels, and BMI were treated as covariates. These variables were selected based on previous research that showed associations with the exposure (i.e., sex, pubertal development) and PA and/or SB (e.g., Lee, An, et al., 2016; Lee \& Spence, 2016). Economic status was determined based on responses to the question, "What is your household's economic status?". The response categories were low, low-to-middle, middle, middle-to-high, and high. Parental education levels were obtained by asking participants to answer their parents' education attainment. The response options were elementary or less ( $\leq 6$ years), middle school ( $7-9$ years), high school (10-12 years), and college and above ( $\geq 13$ years). For analyses, educational attainment of each parent (i.e., father, mother) was categorized into two groups: high school graduate or less and post-secondary graduate or more. Weight and height were self-reported by participants. BMI was computed by dividing weight in kilograms by height in meters squared $\left(\mathrm{kg} / \mathrm{m}^{2}\right)$. Weight status was defined based on the age- and sex -specific BMI reference data for South Korean children and adolescents (Moon et al., 2008). Overweight was defined as BMI percentile 85.0-94.9th, and obesity as BMI percentile $\geq 95.0$ th.

\section{Statistical analysis}

All analyses employed sampling weights provided for the KYRBS. Descriptive statistics summarized the characteristics of the sample, which were given in terms of means and standard deviations or percentages. To examine whether pubertal development mediated the relationship between (i) sex and PA, and (ii) sex and $\mathrm{SB}$, the recommendations suggested by Preacher and Hayes (2008) were followed. As shown in Figure 1, path $c$ is called the total effect. Based on the assumption that the effect of X (sex) on Y (PA or SB) may be mediated by variable $\mathrm{M}$ (pubertal development), path $c$ ' is called the direct effect. An indirect effect or mediation occurs when path $c^{\prime}$ is not significant but paths ab are significant. Complete mediation occurs when variable $\mathrm{X}$ no longer affects $\mathrm{Y}$ after $\mathrm{M}$ has been introduced (path $c^{\prime}=$ zero). Partial mediation occurs when the path from $\mathrm{X}$ to $\mathrm{Y}$ is reduced in absolute size but remains different from zero when the potential mediator is introduced.

Age, economic status, parental education levels, and weight status were included as covariates in all mediation models. Total and direct effects were calculated using multiple linear regressions. Indirect effects were calculated employing a bootstrapping resampling approach. Specifically, the script version of the INDIRECT macro was used to calculate product-of-coefficients and bias-corrected $95 \%$ confidence intervals (BC $95 \% \mathrm{CI}$ ) based on 1,000 resamples. There are four paths in explaining the relationship between sex, pubertal 
Total effect (path c)

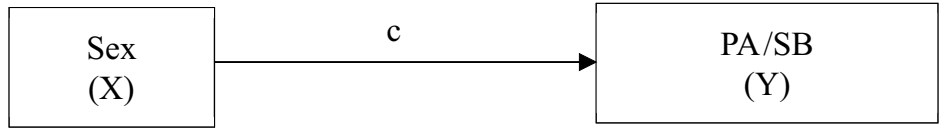

Direct (path c') and indirect effect/mediation model (path ab)

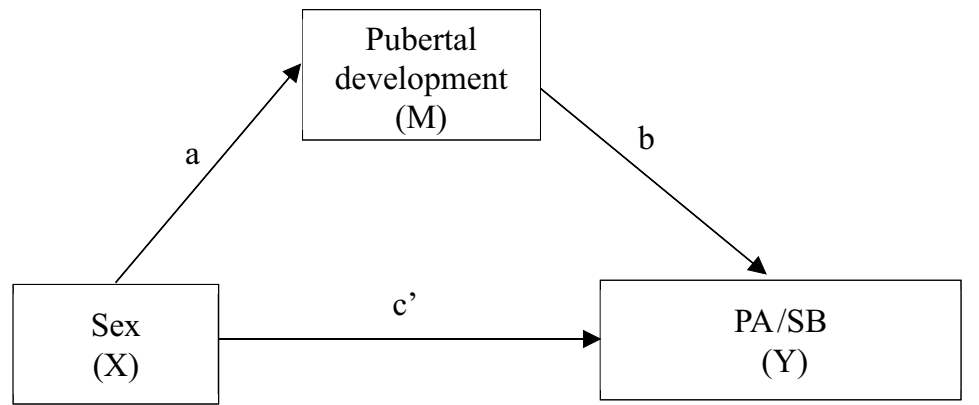

Figure 1. Model of the total, direct, and mediated effect of sex on physical activity (PA) or sedentary behavior (SB). Complete mediation occurs when variable $\mathrm{X}$ no longer affects $\mathrm{Y}$ after $\mathrm{M}$ has been introduced ( path $c^{\prime}=0$ ). Partial mediation occurs when the path from $\mathrm{X}$ to $\mathrm{Y}$ is reduced in absolute size but remains different from zero after the potential mediator is introduced.

development, and PA. Path $c$ indicated the association between sex and PA whereas path c' indicated the association between sex and PA after pubertal development has been introduced in the model. Path $a$ indicated the association between sex and pubertal development, and path $b$ indicated the associations between pubertal development and PA. This mediation model was repeated with SB as a criterion variable. Participants who had not experienced menarche or spermarche were excluded from the mediation analysis. All analyses were conducted using IBM SPSS Statistics (Version 21 for Windows; IBM, Armonk, NY, USA).

\section{Results}

Table 1 shows the whole- and sub-sample characteristics by sex. The mean age of the sample was $14.96 \pm 1.8$ for boys and $14.92 \pm 1.7$ for girls. The proportions of respondents participating in PA for more than $60 \mathrm{~min}$ utes daily were $7.2 \%$ among boys and $2 \%$ among girls respectively. Weighted average time spent in SB per week was higher among girls than boys $(2.11 \pm 1.0 \mathrm{hr}$ /day vs. $1.96 \pm 1.0 \mathrm{hr} /$ day). Among those who had experienced menarche or spermarche $(97.3 \%$ of girls and $74.5 \%$ of boys), the mean grade of menarche or spermarche was $8.13 \pm 1.8$ for boys and $7.27 \pm 1.3$ for girls. The average grade by which menarche/spermarche were achieved were similar to those reported previously (Negriff \& Susman, 2011; Song et al., 2015).
The results from the mediating analyses are shown in Table 2. For the PA model, both the total (c path) $(\beta=-0.58 \pm 0.01 ; p<.001)$ and the direct effect (c' path) $(\beta=-0.58 \pm 0.01 ; p<.001)$ of sex on PA were significant. The path between sex and pubertal development (a path) was significant $(\beta=-0.88 \pm 0.01$; $p<.001)$, however, the path between pubertal development to PA (b path) was not significant $(\beta=0.00 \pm 0.00 ; p=.86)$. The bootstrap analyses with 1,000 samples demonstrated that pubertal development did not mediate the relationship between sex and PA ( $\beta=0.00$; BC 95\% CI [-0.01, 0.01]). Therefore, no indirect effect was observed. In the SB model, both the total (c path) $(\beta=0.18 \pm 0.01 ; p<.001)$ and the direct effect (c' path) $(\beta=0.17 \pm 0.01 ; p<.001)$ of sex on SB were significant. The paths between sex and pubertal development (a path) $(\beta=-0.88 \pm 0.01 ; p<.001)$, and between pubertal timing to SB were significant (b path) $(\beta=-0.01 \pm 0.00 ; p<.001)$. The bootstrap analyses with 1,000 samples demonstrated that pubertal timing significantly mediated the relationship between sex and SB ( $\beta=0.01$; BC 95\% CI [0.00, 0.02]). Therefore, an indirect effect existed between sex and SB via pubertal development, but the effect was small.

\section{Discussion}

This study examined whether pubertal development mediated the associations of sex with PA and SB in 
Table 1

Sample characteristics by sex - Korea Youth Risk Behavior Web-based Survey, 2012

\begin{tabular}{|c|c|c|c|c|}
\hline & \multicolumn{2}{|c|}{ All sample $(N=74,186)$} & \multicolumn{2}{|c|}{ Sub sample ${ }^{\ddagger}(n=53,347)$} \\
\hline & Boys $(n=38,221)$ & Girls $(n=35,965)$ & Boys $(n=19,535)$ & Girls $(n=33,812)$ \\
\hline Age $(M \pm S D)$ & $14.96 \pm 1.8$ & $14.92 \pm 1.7^{*}$ & $15.29 \pm 1.7$ & $15.03 \pm 1.7^{*}$ \\
\hline Height $(M \pm S D)$ & $169.35 \pm 8.3$ & $159.75 \pm 5.5^{*}$ & $170.79 \pm 7.3$ & $159.99 \pm 5.2^{*}$ \\
\hline Weight $(M \pm S D)$ & $60.28 \pm 12.0$ & $51.82 \pm 7.9^{*}$ & $61.55 \pm 11.4$ & $52.37 \pm 7.7 *$ \\
\hline Body mass index $\left(\mathrm{kg} / \mathrm{m}^{2}\right)(M \pm S D)$ & $20.90 \pm 3.3$ & $20.26 \pm 2.7^{*}$ & $21.01 \pm 3.2$ & $20.43 \pm 2.6^{*}$ \\
\hline Overweight $(\geq 85)^{\dagger}$ & 14.6 & 7.4 & 14.4 & 8.0 \\
\hline Menarche or spermarche obtained (\%) & 74.5 & 97.3 & 100 & 100 \\
\hline Average grade of pubertal development & - & - & $8.13 \pm 1.8$ & $7.27 \pm 1.3^{*}$ \\
\hline \multicolumn{5}{|l|}{ School type $(\%)^{\S}$} \\
\hline Middle school & 48.7 & 49.4 & 40.6 & 47.2 \\
\hline Regular high school & 39.3 & 39.2 & 45.9 & 41.2 \\
\hline Specialized high school & 12.0 & 11.4 & 13.6 & 11.7 \\
\hline \multicolumn{5}{|l|}{ Economic status $(\%)$} \\
\hline Low & 8.3 & 5.0 & 7.2 & 4.4 \\
\hline Low to middle & 25.1 & 22.7 & 24.1 & 22.0 \\
\hline Middle & 44.7 & 48.9 & 44.9 & 49.4 \\
\hline Middle to high & 16.6 & 18.6 & 18.0 & 19.2 \\
\hline High & 5.4 & 4.7 & 5.7 & 5.0 \\
\hline \multicolumn{5}{|l|}{ Parental education (\%) } \\
\hline Father $\geq$ post-secondary graduate & 55.6 & 53.9 & 52.3 & 51.7 \\
\hline Mother $\geq$ post-secondary graduate & 52.8 & 47.2 & 40.9 & 39.7 \\
\hline \multicolumn{5}{|l|}{ Physical activity/week (\%) } \\
\hline None & 27.9 & 46.8 & 26.2 & 47.1 \\
\hline 1 day & 15.4 & 19.1 & 15.8 & 19.2 \\
\hline 2 days & 16.4 & 14.4 & 17.4 & 14.4 \\
\hline 3 days & 13.8 & 9.6 & 15.0 & 9.5 \\
\hline 4 days & 8.3 & 4.0 & 8.2 & 3.9 \\
\hline 5 days & 7.5 & 3.0 & 7.3 & 2.9 \\
\hline 6 days & 2.6 & 1.0 & 2.8 & 1.0 \\
\hline 7 days & 7.2 & 2.0 & 7.3 & 2.0 \\
\hline Physical activity/week $(M \pm S D)$ & $3.30 \pm 2.1$ & $2.29 \pm 1.7$ & $3.33 \pm 2.1$ & $2.29 \pm 1.7$ \\
\hline \multicolumn{5}{|l|}{ Sedentary behavior (\%) } \\
\hline \multicolumn{5}{|l|}{ Weekdays } \\
\hline$<1$ hour & 22.9 & 20.9 & 23.5 & 21.0 \\
\hline $1-2$ hours & 31.7 & 28.4 & 32.0 & 28.2 \\
\hline $2-3$ hours & 23.3 & 22.7 & 23.0 & 22.4 \\
\hline 3-4 hours & 10.2 & 12.0 & 9.7 & 12.0 \\
\hline$\geq 4$ hours & 11.9 & 16.0 & 11.8 & 16.4 \\
\hline \multicolumn{5}{|l|}{ Weekend days } \\
\hline$<1$ hour & 11.3 & 9.4 & 10.8 & 9.3 \\
\hline $1-2$ hours & 20.9 & 17.8 & 20.2 & 17.4 \\
\hline $2-3$ hours & 25.8 & 23.5 & 26.1 & 22.9 \\
\hline 3-4 hours & 17.1 & 18.9 & 17.3 & 18.9 \\
\hline$\geq 4$ hours & 24.8 & 30.4 & 25.5 & 31.5 \\
\hline $\begin{array}{l}\text { Total sedentary behavior } \\
([\text { weekday } \times 5+\text { weekend day } \times 2] / 7) \\
\text { (hour) }(M \pm S D)\end{array}$ & $2.75 \pm 1.2$ & $2.93 \pm 1.2^{*}$ & $2.75 \pm 1.2$ & $2.95 \pm 1.2^{*}$ \\
\hline
\end{tabular}

Note. Data are represented as mean \pm standard deviation $(M \pm S D)$ or percentage $(\%)$.

${ }^{\dagger}$ Overweight $\geq 85$ percentile calculated based on the 2007 BMI-for-age in Korean children and adolescents (Moon et al., 2008). *Excluding those who have not yet experienced menarche or spermarche.

${ }^{\S}$ Regular high schools include public or private, science, foreign language or international, art and sports schools; specialized high schools include school specifically focused on education in agriculture, manufacturing, and technology. ${ }^{*} p<.001$ for significant sex difference. 
Table 2

Total, direct, and indirect effects of the relationships between (1) sex, pubertal development, and physical activity (PA), and (2) sex, pubertal development, and sedentary behavior (SB) - Korea Youth Risk Behavior Web-based Survey, $2012(n=53,347)$

\begin{tabular}{|c|c|c|c|c|c|}
\hline $\begin{array}{l}\text { Criterion } \\
\text { variable }\end{array}$ & $\begin{array}{l}\text { Sex to pubertal devel- } \\
\text { opment (a path) } \\
\text { Coefficient }^{*}(S E)\end{array}$ & $\begin{array}{l}\text { Pubertal development } \\
\text { to PA/SB (b path) } \\
\text { Coefficient }(S E)\end{array}$ & $\begin{array}{l}\text { Total effect of sex on } \\
\text { PA/SB (c path) } \\
\text { Coefficient }(S E)\end{array}$ & $\begin{array}{l}\text { Direct effect of sex on } \\
\text { PA/SB (c' path) } \\
\text { Coefficient }(S E)\end{array}$ & $\begin{array}{c}\text { Bootstrap results for } \\
\text { indirect effect }(\mathrm{ab})^{\dagger} \\
\alpha \beta^{\S}(S E)[95 \% \mathrm{CI}]\end{array}$ \\
\hline PA & $-0.88(0.01)^{*}$ & $0.00(0.00)$ & $-0.58(0.01)^{*}$ & $-0.58(0.01)^{*}$ & $\begin{array}{l}0.00(0.00) \\
{[-0.01, .01]}\end{array}$ \\
\hline $\mathrm{SB}^{1}$ & $-0.88(0.01)^{*}$ & $-0.02(0.00)^{*}$ & $0.18(0.01)^{*}$ & $0.17(0.01)^{*}$ & $\begin{array}{l}0.01(0.00) \\
{[0.00,0.02]}\end{array}$ \\
\hline
\end{tabular}

Note. All analyses excluded students who have not experienced menarche or spermarche and were controlled for age, economic status, parental education levels, and weight status. $S E=$ standard error.

${ }^{\dagger}$ Bootstrap results based on 1,000 resamples.

*Product-of-coefficient estimate.

${ }^{\S} \alpha \beta=$ unstandardized regression coefficient.

"Sedentary behavior included watching television, playing video games, surfing the net, and chatting with friends. ${ }^{*} p<.001$.

a representative sample of Korean adolescents. Our findings indicated that pubertal development did not mediate the relationship between sex and PA. Pubertal development partially mediated the relationship between sex and SB, the effect was small.

The key finding of this study is the apparent sex differences in PA among Korean adolescents, even after the inclusion of pubertal development as a mediator in the regression model. This is largely inconsistent with the previous findings from samples of American, British, Canadian and Portuguese adolescents (Cumming et al., 2008; Rodrigues et al., 2010; Sherar et al., 2007; Thompson et al., 2003). Such inconsistency may be explained by sociocultural factors associated with PA. Specifically, traditional gender roles in Korea reinforced by Confucianism expect girls to be well-behaved and "girly (e.g., passive, nurturing)"; such cultural factors may reduce opportunities for girls being physically active (Im \& Choe, 2004). Accordingly, a number of studies suggested that gender inequality in a PE setting is one of the barriers to PA among Korean girls (Lee, Spence, Song, \& Jeon, 2015). Specifically, the contents (i.e., textbook) and evaluation of the PE curriculum in South Korea are more geared towards boys than girls, and PE teachers, mostly males, were more actively engaging with boys than girls in a co-ed setting (Lee et al., 2015). Malina (2008) argued that PA among adolescents is influenced by cultural factors that attached differing values and meanings to various types of PA. Incorporating such sociocultural factors (e.g., gender roles, gender stereotypes, gender-based discrimination in PA settings) as well as individual-level differences other than biological factors (e.g., psychological correlates of PA) is recommended for future studies aiming to better understand sex differences in PA among South Korean adolescents. Though sex differences in SB were partially explained by pubertal development, the effect was trivial. According to the results of the 2016 South Korea's Report Card on Physical Activity for Children and Youth (Song et al., 2016), SB was given a $F$ grade due to high sitting time in and out of school among Korean adolescents. Specifically, the country's internationally well-known "education fever" and the academic pressure that was put on adolescents, they spend 15 hour/day studying (ICEF Monitor, 2014, January 23). Korean adolescents also tend to prefer sedentary pursuits when they are not studying. For example, in a recent study comparing leisure type preference among adolescents in China, Japan, and Korea, the most preferred leisure activity among Korean adolescents was surfing the net/playing video games $(58.2 \%$ in boys and $36.4 \%$ in girls) (Lee, Yi, Walker, \& Spence, 2016). Though a previous study reported an indirect effect of BMI on SB for boys only (Lee \& Spence, 2016), pubertal development alone may not fully explain variations in SB among Korean adolescents. Rather, the sociocultural context of Korea emphasizing the importance of education should be considered.

Overall, the prevalence of engaging in PA appears to be low regardless of sex among Korean adolescents. Based on the finding of this study, only $7.2 \%$ of boys and $2 \%$ of girls met the recommended level of PA as defined by the WHO (2010) (i.e., 60 minutes of moderate- to vigorous-intensity PA daily). Furthermore, given that self-reported PA is often an over estimate of actual PA (Adamo, Prince, Tricco, Connor-Gorber, \& Tremblay, 2009), the compliance to the PA guidelines among Korean adolescents may be even lower when PA is measured by accelerometry. Contrary to the findings for PA, girls spent more time in SB than boys. These results, combined with our main results, may have important implications for health promotion 
in Korea. First, efforts to increase PA and reduce SB should put a particular emphasis on female adolescents given the apparent sex differences in these behaviors. Furthermore, rather than biological sex per se, understanding of the differences in PA and SB between boys and girls may be more appropriate from a perspective of gender which is defined as a socially and culturally constructed state of being male and female. Therefore, future research should examine issues and challenges associated with gender in various PA contexts.

The strengths of this study include a representative sampling design, a large sample size, and the use of contemporary mediation analytic method (i.e., bootstrapping). Nonetheless, several limitations should be acknowledged. Data were collected through a selfadministered questionnaire in which students may have over reported their PA levels and under reported their SB. Though using an objective measure (e.g., accelerometer, heart-rate monitor, and pedometer) would more accurately capture the levels of PA and SB, it would be challenging and costly in such a large sample of over 70,000 adolescents. In addition, though PA was measured using single-item, it can be a valid screening tool in large-scale epidemiological studies (Johansson \& Westerterp, 2008; Milton, Clemes, \& Bull, 2013). Age at menarche and age at spermarche were employed to estimate pubertal development. Though these measures have shortcomings, self-ratings of pubertal status are considered acceptable in large population-based studies (Dorn et al., 2006). Though it is also important to note that the inconsistency of findings between this study and previous studies (Cumming et al., 2008; Rodrigues et al., 2010; Sherar et al., 2007; Thompson et al., 2003) may simply be due to the different measures employed to assess pubertal development, this study was the first attempt to examine the potential role of pubertal development on sex differences in PA and SB among Korean adolescents, which is largely under-studied population group.

\section{Conclusions}

In summary, sex appears to be an important predictor PA and SB. Nonetheless, it is most likely that a combination of individual (e.g., psychological, biological) and sociocultural factors contribute to adolescents' behavior. Therefore, such factors should be taken into consideration in future studies examining sex differences in PA and SB. Furthermore, the results of this study contribute to diversifying the literature by adding information from the non-WEIRD (Westernized, educated, industrialized, rich, and democratic) population (Henrich, Heine, \& Norenzayan, 2010).

\section{Acknowledgment}

This research was supported by an Obesity Training Grant from the Canadian Institutes of Health Research, and the Korea Project Fund from the University of Alberta International.

\section{Conflict of interest}

There were no conflicts of interest.

\section{References}

Adamo, K. B., Prince, S. A., Tricco, A. C., Connor-Gorber, S., \& Tremblay, M. (2009). A comparison of indirect versus direct measures for assessing physical activity in the pediatric population: A systematic review. International Journal of Pediatric Obesity, 4, 2-27.

Bitar, A., Vernet, J., Coudert, J., \& Vermorel, M. (2000). Longitudinal changes in body composition, physical capacities and energy expenditure in boys and girls during the onset of puberty. European Journal of Nutrition, 39, 157-163.

Carson, V., Hunter, S., Kuzik, N., Gray, C. E., Poitras, V. J., Chaput, J. P., ... Kho, M. E. (2016). Systematic review of sedentary behavior and health indicators in school-aged children and youth: An update 1. Applied Physiology, Nutrition, and Metabolism, 41, S240-S265.

Colley, R. C., Garriguet, D., Janssen, I., Craig, C. L., Clarke, J., \& Tremblay, M. S. (2011). Physical activity of Canadian children and youth: Accelerometer results from the 2007 to 2009 Canadian Health Measures Survey. Health Reports, 22, 1-9.

Colley, R. C., Garriguet, D., Janssen, I., Wong, S. L., Saunders, T. J., Carson, V., \& Tremblay, M. S. (2013). The association between accelerometer-measured patterns of sedentary time and health risk in children and youth: Results from the Canadian Health Measures Survey. BMC Public Health, 13, 200-208.

Cumming, S. P., Sherar, L. B., Pindus, D. M., Coelho-e-Silva, M. J., Malina, R. M., \& Jardine, P. R. (2012). A biocultural model of maturity-associated variance in adolescent physical activity. International Review of Sport and Exercise Psychology, 5, 23-43.

Cumming, S. P., Standage, M., Gillison, F., \& Malina, R. M. (2008). Sex differences in exercise behavior during adolescence: Is biological maturation a confounding factor? Journal of Adolescent Health, 42, 480-485.

Dorn, L. D., Dahl, R. E., Woodward, H. R., \& Biro, F. (2006). Defining the boundaries of early adolescence: A user's guide to assessing pubertal status and pubertal timing in research with adolescents. Applied Developmental Science, 10, 30-56.

Eisenmann, J. C., \& Wickel, E. E. (2009). The biological basis of physical activity in children: Revisited. Pediatric Exercise Science, 21, 257-272.

Goran, M. I., Gower, B. A., Nagy, T. R., \& Johnson, R. K. (1998). Developmental changes in energy expenditure 
and physical activity in children: Evidence for a decline in physical activity in girls before puberty. Pediatrics, 101, 887-891.

Henrich, J., Heine, S. J., \& Norenzayan, A. (2010). Most people are not WEIRD. Nature, 466, 29.

ICEF Monitor. (2014, January 23). High performance, high pressure in South Korea's education system. Retrieved from http://monitor.icef.com/2014/01/high-performance-highpressure-in-south-koreas-education-system/

Im, E.-O., \& Choe, M.-A. (2004). Korean women's attitudes toward physical activity. Research in Nursing \& Health, 27, 4-18.

Johansson, G., \& Westerterp, K. R. (2008). Assessment of the physical activity level with two questions: Validation with doubly labeled water. International Journal of Obesity, 32, 1031-1033.

Kim, Y., Choi, S., Chun, C., Park, S., Khang, Y.-H., \& Oh, K. (2016). Data resource profile: The Korea Youth Risk Behavior Web-based Survey (KYRBS). International Journal of Epidemiology, 45, 1076-1076e.

Korea Centers for Disease Control and Prevention. (2009). Reliability and validity of the Korea Youth Risk Behavior Web-based Survey Questionnaire. Cheongwon, South Korea: Korea Centers for Disease Control and Prevention.

Korea Centers for Disease Control and Prevention, Ministry of Education, Science and Technology, \& Ministry of Health and Welfare. (2012). The Eighth Korea Youth Risk Behavior Web-based Survey: Survey summaries. Cheongwon, South Korea: Korea Centers for Disease Control and Prevention.

Leatherdale, S. T., \& Harvey, A. (2015). Examining communication and media-based recreational sedentary behaviors among Canadian youth: Results from the COMPASS study. Preventive Medicine, 74, 74-80.

Lee, E.-Y., An, K., Jeon, J., Rodgers, W., Harber, V., \& Spence, J. (2016). Biological maturation and physical activity in South Korean adolescent girls. Medicine \& Science in Sports \& Exercise, 48, 2454-2461.

Lee, E.-Y., \& Spence, J. C. (2016). Pubertal development and screen time among South Korean adolescents: Testing body mass index and psychological well-being as mediators. Global Health Research and Policy, 1, 19.

Lee, E.-Y., Spence, J. C., Song, Y. K., \& Jeon, J. Y. (2015). A systematic review of the correlates of Korean girls' physical activity: An ecological perspective. Health and Social Science, 40, 5-28.

Lee, E.-Y., Yi, K. J., Walker, G. J., \& Spence, J. C. (2016). Preferred leisure type, value orientations, and psychological well-being among East Asian youth. Leisure Sciences. Advance online publication. doi:10.1080/01490400.2016.1209139

Malina, R. M. (2008). Biocultural factors in developing physical activity levels. In A. L. Smith \& S. J. H. Biddle (Eds.), Youth physical activity and sedentary behavior (pp. 141-166). Champaign, IL: Human Kinetics.

Milton, K., Clemes, S., \& Bull, F. (2013). Can a single question provide an accurate measure of physical activity? British Journal of Sports Medicine, 47, 44-48.

Moon, J. S., Lee, S. Y., Nam, C. M., Choi, J.-M., Choe, B.-K., Seo, J.-W., ... Lee, C. G. (2008). 2007 Korean National
Growth Charts: Review of developmental process and an outlook. Korean Journal of Pediatrics, 51, 1-25.

Negriff, S., \& Susman, E. J. (2011). Pubertal timing, depression, and externalizing problems: A framework, review, and examination of gender differences. Journal of Research on Adolescence, 21, 717-746.

Patton, G. C., \& Viner, R. (2007). Pubertal transitions in health. Lancet, 369, 1130-1139.

Poitras, V. J., Gray, C. E., Borghese, M. M., Carson, V., Chaput, J. P., Janssen, I., ... Sampson, M. (2016). Systematic review of the relationships between objectively measured physical activity and health indicators in school-aged children and youth 1. Applied Physiology, Nutrition, and Metabolism, 41, S197-S239.

Preacher, K. J., \& Hayes, A. F. (2008). Asymptotic and resampling strategies for assessing and comparing indirect effects in multiple mediator models. Behavior Research Methods, 40, 879-891.

Rodrigues, A. M., Silva, M. J. C. E., Mota, J., Cumming, S. P., Sherar, L. B., Neville, H., \& Malina, R. M. (2010). Confounding effect of biologic maturation on sex differences in physical activity and sedentary behavior in adolescents. Pediatric Exercise Science, 22, 442-453.

Sherar, L. B., Cumming, S. P., Eisenmann, J. C., BaxterJones, A. D., \& Malina, R. M. (2010). Adolescent biological maturity and physical activity: Biology meets behavior. Pediatric Exercise Science, 22, 332-349.

Sherar, L. B., Esliger, D. W., Baxter-Jones, A. D., \& Tremblay, M. S. (2007). Age and gender differences in youth physical activity: Does physical maturity matter? Medicine \& Science in Sports \& Exercise, 39, 830-835.

Song, Y., Ma, J., Wang, H.-J., Wang, Z., Lau, P. W. C., \& Agardh, A. (2015). Age at spermarche: 15-year trend and its association with body mass index in Chinese schoolaged boys. Pediatric Obesity, 11, 369-374.

Song, Y., Yang, H. I., Lee, E.-Y., Yu, M.-S., Kang, M. J., Kang, H. J., ... Jeon, J. Y. (2016). Results from South Korea's 2016 Report Card on Physical Activity for Children and Youth. Journal of Physical Activity and Health, 13(Suppl. 2), S274-S278.

Thompson, A. M., Baxter-Jones, A. D., Mirwald, R. L., \& Bailey, D. A. (2003). Comparison of physical activity in male and female children: Does maturation matter? Medicine \& Science in Sports \& Exercise, 35, 1684-1690.

Troped, P. J., Wiecha, J. L., Fragala, M. S., Matthews, C. E., Finkelstein, D. M., Kim, J., \& Peterson, K. E. (2007). Reliability and validity of YRBS physical activity items among middle school students. Medicine \& Science in Sports \& Exercise, 39, 416-425.

World Health Organization. (2010). Global recommendations on physical activity for health 2010. Retrieved from http:// whqlibdoc.who.int/publications/2010/9789241599979_ eng.pdf

World Health Organization. (2011). The sexual and reproductive health of younger adolescents: Research issues in developing countries 2011. Retrieved from http://whqlibdoc.who. int/publications/2011/9789241501552_eng.pdf

Youth Risk Behavior Surveillance System. (2016, August 11). Retrieved from http://www.cdc.gov/HealthyYouth/ yrbs/index.htm 